\title{
Size variation, allometry and mating success in Aotearoa|New Zealand kelp flies (Coelopidae)
}

\author{
Rebecca J. LeGrice ${ }^{1,2} \mathbb{D} \cdot$ Gregory I. Holwell ${ }^{1}$
}

Received: 7 September 2021 / Accepted: 24 January 2022 / Published online: 24 February 2022

(C) The Author(s) 2022

\begin{abstract}
The need to respond quickly to the presence of an ephemeral resource required for breeding is often a feature of scramble competition mating systems. Scramble competition mating systems can feature extreme levels of sexual conflict and coercive mating by males. As a result, sexual selection can act on various traits used by males to overcome female resistance behaviours. Selection on these traits may result in significant intra and intersexual size variation and sexual dimorphism. Additionally, traits that influence mating success in males often show positive static allometry. Kelp flies (Coelopidae) are a small family of Diptera which specialise on wrack (beach cast marine macroalgae), a highly ephemeral resource. The mating system of these flies involves high levels of sexual conflict, with females rejecting all male mating attempts. In this study we describe intra and intersexual size variation and static allometry of traits in two of AotearoalNew Zealand's species, Coelopella curvipes and Chaetocoelopa littoralis. In addition, we investigate the mating behaviour of $C$. littoralis under ecologically relevant mating conditions. We found high levels of variation in both species with significant evidence of sexual dimorphism across all traits measured in $C$. littoralis, and in mid tibia length in $C$. curvipes. Furthermore, mid tibia length in both species exhibits positive static allometry and is disproportionally larger in larger males, suggesting that this trait in particular may be under strong sexual selection. We found that larger male $C$. littoralis which attempt to mate are significantly more likely to mate successfully demonstrating a large-size advantage in this species similar to findings across the Coelopidae. However, we only found a non-significant trend towards a mating advantage for males with longer mid-tibiae. We discuss these findings with reference to the population dynamics and ecology of these species.
\end{abstract}

Keywords Allometry $\cdot$ Mating behaviour $\cdot$ Scramble competition $\cdot$ Wrack $\cdot$ Sexual selection

Rebecca J. LeGrice

rlegrice@canterburymuseum.com

1 Te Kura Mātauranga Koiora, School of Biological Sciences, Te Whare Wānanga o Tāmaki

Makaurau, University of Auckland, Auckland, New Zealand

2 Current Address: Canterbury Museum, Christchurch 8013, New Zealand 


\section{Introduction}

Interactions between females and males can be heavily influenced by evolutionary conflicts of interest between the two sexes (Arnqvist and Rowe 2005; Chapman et al 2003; Parker 1979). Rarely do females and males exhibit the same optima in mating rate and duration (Parker 1979). Females tend to benefit from mating with fewer, high quality mates, while males benefit most from mating with as many females as possible (Andersson 1994; Arnqvist and Rowe 2005; Kirkpatrick 1982). Owing to this sexual conflict, mating interactions among diverse animal taxa can involve energetic and lengthy premating struggles (FowlerFinn et al 2014; Olsson 1995; Weigensberg and Fairbairn 1994). In such encounters, females frequently reject male mating attempts using stereotypical rejection behaviours such as shaking, kicking and abdomen curling (Eberhard 2002; Parker 1972a). For example, owing to the harm caused during copulation, female Callosobruchus maculatus seed beetles violently kick males during mating leading to shorter copula durations (Crudgington and Siva-Jothy 2000). In the face of such female rejection behaviours, males must use coercive strategies, often involving specific morphological adaptations to facilitate the commencement and continuation of copulation, while overcoming female resistance. For example, modified legs, genitalia and antennae are used by males of various insect species to grasp females during mating, and prevent dislodgement during premating struggles (Arnqvist and Rowe 2002; Hosken and Stockley 2004).

A number of hypotheses have been put forward to explain the prevalence of female rejection behaviour and the benefit females gain from frequently and sometimes consistently rejecting male mating attempts (Arnqvist and Rowe 2005; Blyth and Gilburn 2011; Chapman et al 2003; Parker 1979). The female reluctance hypothesis, is closely tied to the concept of sexual conflict and male-imposed harm, suggesting that rejection acts to reduce mating rate when mating itself is costly (Blanckenhorn et al 2002; Crudgington and SivaJothy 2000). Alternatively, the screening hypothesis proposes that rejection itself selects for those males who can overcome resistance, and effectively functions as mate choice for male coercion and persistence. Lastly, the communication hypothesis suggests that in resisting, females are simply communicating a lack of receptivity and reluctance to mate rather than to reduce harm (Baena and Eberhard 2007; Briceño and Eberhard 2017; Dutto et al 2011).

As explained above, males use a variety of morphological structures, from genital claspers to elongated legs, to highly modified antennae to overcome female resistance to mating. Such traits have the potential to strongly influence lifetime mating success and are therefore likely to be subject to potent sexual selection (Arnqvist and Rowe 2005). However, in contrast to the vast literature on male morphological structures that function as ornaments influencing female mate choice, (Andersson 1986, 1994; Mead and Arnold 2004; Moller and Pomiankowski 1993), and weapons, influencing success in male agonistic interactions (Emlen et al 2012), the analysis of patterns of variation in male coercive traits has received less attention. Three common differences between males and females are commonly shown for sexually selected weapons and ornaments. Firstly, sexual size and shape dimorphism commonly occurs in such structures with the most common pattern being larger size and more modification in male traits (Fea and Holwell 2018a, b; Geist and Bayer 1988; RicoGuevara and Hurme 2019). Secondly, higher coefficients of variation (CV\%) in males than in females for equivalent traits (O'Brien et al 2018). Lastly, positive static allometry is often observed for male traits (Eberhard et al 2018; O'Brien et al 2018; but see Bonduriansky 2007). 
Static allometries describe patterns of trait variation relative to body size among individuals of the same species and the same developmental stage (Gould 1966). Huxley and Tessier (1936) originally defined scaling relationships such that isometry occurs when traits scale proportionally with body size and the scaling exponent of the relationship between trait size and body size is one. When this exponent is less than one, the relationship is described as negative allometry or hypoallometry. When the exponent is greater than one, the relationship is described as positive allometry or hyperallometry. The positive allometry observed for many male traits (Kodric-Brown et al 2006) therefore highlights that in these cases, large males exhibit disproportionally large traits compared with small males, and this frequently contrasts with isometry for homologous traits in females, or in other male reference traits (O'Brien et al. 2018). Bonduriansky and Day (2003) provide a useful framework for interpreting allometries, based on net selection and showed that positive static allometry evolves when the marginal fitness gains of investing disproportionately in a trait is greater for larger individuals than it is for smaller individuals.

While the three patterns outlined above (SSD, higher male trait CV\%, positive male static trait allometry) are all commonly observed for weapons and ornaments, whether these patterns hold for male grasping or coercive structures is relatively unknown. Larger relative size in male structures (SSD) has been observed for a number of coercive traits. For example, the highly modified legs and antennae of male Rheumatobates rileyi water striders, are longer, more robust and shaped such as to allow them to grasp onto females during mating struggles and lift the female abdomen to facilitate mating (Khila et al 2012; Rowe et al 2006). Similarly, various Sepsid flies have larger and modified male fore- and midlegs to assist grasping of females during mating struggles and copulation (Eberhard 2001; Parker 1972b; Puniamoorthy et al 2008; Rohner and Blanckenhorn 2018). While positive allometry is commonly observed for sexually selected traits (O'Brien et al 2018; Petrie 1992), it is not a universal indicator for the influence of sexual selection and many non-sexual traits show positive allometry, while many sexually selected traits do not (Bonduriansky 2007; Eberhard et al 2018). Therefore, whether or not coercive traits that males possess that allow them to overcome female resistance exhibit positive static allometry, depends on whether large males gain disproportionately from investing in large traits.

Known as the true kelp flies - or seaweed flies - the Acalypterate Diptera family Coelopidae are small to large flies (with body length ranging from approximately $3-16 \mathrm{~mm}$ ) with robust, laterally depressed bodies (Mathis and McAlpine 2011). Coelopidae breed on wrack - marine debris dominated by macroalgae which washes ashore forming strandlines - and are found worldwide (Burnet 1960; Cullen et al 1987; Dobson 1974; Egglishaw 1960; Mathis and McAlpine 2011; McAlpine 1991). Coelopids are attracted to and arrive at freshly deposited wrack within a few hours (Dobson 1974). Adult females lay their eggs onto the wrack and the larvae feed within the wrack bed before pupating below or near the wrack bed (Dobson 1974; Egglishaw 1960).

Research into the mating behaviour of Coelopids has focused closely on the prevalence of extreme sexual conflict, with strong female resistance in the form of pre-mating struggles, and convenience polyandry (Day and Gilburn 1997). Female Coelopids are known to remate regularly and mating rate does not appear to change with time (Crean et al 2000; Shuker and Day 2001; Weall and Gilburn 2000) (Blyth and Gilburn 2006). Overall however, female Coelopids are reluctant to mate with any male and always display a strong rejection response consistent with the female reluctance hypothesis, where selection for large male size is driven by female reluctance to engage in costly mating behaviour (Arnqvist 1992; Crean et al 2000; Day and Gilburn 1997; Rowe 1992; Weall and Gilburn 2000). Male Coelopids are only therefore able to gain mating success once the cost of the female 
rejection response passes the threshold of the cost of mating (Blackenhorn et al. 2000; Blyth and Gilburn 2006; Rowe 1992; Thornhill and Alcock 1983).

Intra- and inter-sexual size variation has been described in Coelopid species, with males generally found to be larger and displaying greater variation compared to females (Burnet 1960; Butlin and Day 1985; Crean et al 2000; Crean and Gilburn 1998; Cullen et al 1987; Egglishaw 1960; Gilburn and Day 1994; Mathis and McAlpine 2011; McAlpine 1991). Coelopids also display clear sexual dimorphism in appearance (McAlpine 1991). In some species (e.g. C. frigida), males tend to be more bristly or 'robust' than females(Burnet 1960; Cullen et al 1987; Mayhew 1939; McAlpine 1991), while in others, the bristles on males (including Gluma nitida, Amma blancheae, Chaetocoelopa sydneyensis, and Baeopterus spp.) are reduced compared to females (McAlpine 1991). Although none of these studies assessed the allometric relationships of any traits in Coelopids, there are unpublished studies of positive allometry of male midlegs in $C$. frigida and $C$. pilipes (Andre Gilburn - pers. comm.).

Here we aim to describe the variation in size, sexual dimorphism, and allometry of two species of Coelopid, Coelopella curvipes (Hutton 1902) and Chaetocoelopa littoralis (Hutton 1881), from AotearoalNew Zealand that have received little attention in comparison to species from other parts of the world. This includes comparing the allometries of and variation in body size traits (wing length and thorax width), and in a trait which may influence the outcome of premating struggles (midleg length). Furthermore, we aim to describe the mating behaviour and assess correlates of male-mating success in C. littoralis.

\section{Methods}

Flies were measured under a microscope using modified digital callipers. Minuten pins, (commonly used in insect pinning), were glued to each of the calliper jaws to functionally extended them, providing a far more delicate pair of points to use in measurements. Preliminary measurements of a wide range of traits in both species indicated that leg length in males, and particularly midleg length may vary from that of females. In addition, measurements of the wings and main body segments including head width and thorax length and width appeared to not vary significantly between the sexes. Therefore, to investigate size variation we chose to measure four traits that captured the highest and lowest amounts of variation between the sexes. These measurements included wing length (length from the base of the subcosta to the tip of the wing), thorax width (maximum width), mid-femur length, and mid-tibia length (maximum length of the femur and tibia of the middle legs), and were taken in millimetres to the nearest $0.01 \mathrm{~mm}$. All C. curvipes measured were wild caught flies $(\mathrm{n}=45$ females, $\mathrm{n}=29$ males), whereas $C$. littoralis were from a lab population $(\mathrm{n}=218$ females, $\mathrm{n}=218$ males). All flies, including the those used to start the lab population were collected from a coastal site $\left(36^{\circ} 16^{\prime} 12.4^{\prime \prime S} 174^{\circ} 47^{\prime} 46.2^{\prime \prime E}\right)$ near the township of Leigh, Auckland, New Zealand. To establish the lab population of C. littoralis, we collected 20L buckets of wrack containing both adult flies and larvae and placed these in large mesh cages $(60 \mathrm{~cm} \times 60 \mathrm{~cm} \times 90 \mathrm{~cm})$. As each generation of adult flies died and a new generation began to emerge the population was supplied with fresh 20L buckets of kelp (Ecklonia sp.) collected at low tide when it was able to be taken from the many rocky reefs in the Hauraki Gulf area of Auckland. The population was housed in a rooftop greenhouse which was relatively open to the outside environment so that the flies were exposed to natural light and temperatures. During summer we sprayed the kelp with filtered seawater 
periodically to prevent it from drying out. Finally, we provided the adult flies with a 5\% sucrose solution (after Crean et al 2000) to feed on.

\section{Analyses: trait variation in Chaetocoelopa littoralis and Coelopella curvipes}

To investigate size variation and sexual dimorphism we calculated the average, maximum, minimum, and coefficients of variation for both males and females in both species. We used a two-tailed Z-test to compare the coefficients of variation between males and females for each trait, to assess significance by comparing the calculated values to the critical values of the t-distribution with infinite degrees of freedom (Zar 1999). In addition, we tested for the degree of sexual size dimorphism between average trait sizes for males and females of each species using a Welch t-test (Lovich and Gibbons 1992). Furthermore, we compared the variation in wing length with each of the three measurements (thorax width, mid femur length, and mid tibia length) between sexes of each species. All of the measurements were $\log$ transformed prior to analysis. To assess the static allometry of these traits for these species we used ordinary least squares (OLS) regression to calculate coefficients (intercept and slope) and tested for a difference in the intercept and slope between males and females and for each sex against an isometric slope. OLS regression is recommended as the most appropriate method for analyses of allometric relationships where measurement error is known to be low (Kilmer and Rodríguez 2017). All analyses were carried out in $\mathrm{R}$ ( $\mathrm{R}$ Core Team, 2020).

\section{Mating behaviour in Chaetocoelopa littoralis}

Mating behaviour trials were only carried out with $C$. littoralis because a lab population could not be successfully established for $C$. curvipes. Pupa of $C$. littoralis were hand collected from a lab population prior to eclosion and placed in a mesh cage. Each day we removed all newly emerged adults keeping them separated by sex and eclosion date to ensure all adults were of a similar age in mating trials. Adults were not used in mating trials until at least $48 \mathrm{~h}$ old to ensure that they were sexually mature.

Trial mating experiments found that unlike other Coelopid species C. littoralis did not mate readily when there are only a small number of flies present. Consequently, we found that approximately 20 flies (with an even sex ratio) were required before mating behaviour was likely to be observed. All subsequent mating trials were carried out in a small mesh cage $(60 \mathrm{~cm} \times 30 \mathrm{~cm} \times 30 \mathrm{~cm})$ with a clear observation window on one side. Finally, during trials we placed the mesh cage over a tray of fresh kelp, as it has been found to stimulate mating behaviour in other species (Dunn and Crean 2002; Edward and Gilburn 2007).

In each mating trial we used 10 randomly selected flies of each sex which had eclosed within 10 days, and within five days of each other. Although there can be significant variation in both the density and sex ratio of wild population, this chosen density and 1:1 sex ratio for trials fits within the natural range for this species. Prior to being placed into the mating arena, flies were anaesthetised using a $\mathrm{CO}_{2}$ Fly Pad (MINJ-DROS-FP, Tritech Research) and then individually marked using non-toxic paint pens (POSCA) and placed into separate small containers to recover. Four different colours of marker were used with different spot and stripe combinations on the thorax so that flies could be individually identified. Once marked, the flies were left for a minimum of $15 \mathrm{~min}$ to recover after which they had returned to normal behaviour. The flies were then all released into the mating arena and observed for one hour. We recorded all mating attempts using a speech to text dictation application (Dictation 
- Speech to text, developed by Christian Neubauer (C) 2021 IBN Software), including the individual identification of the male and female, if the male managed to overcome the female rejection response, and whether they successfully mated with the female during the interaction. In cases where multiple males attempted to copulate with the same female each male was recorded as a separate mating attempt with the female and a note was made that multiple males were involved.

A total of 16 groups of 20 flies each with an even sex ratio were observed from August - October 2019. After mating trials were complete, a number of body size measurements were taken from all of the flies in the trials including wing length, mid tibia length, mid femur length, and thorax width using the method described above.

\section{Analyses: mating success with size}

We used the first mating trials of all groups for analyses to test for a size difference between males that (1) did and did not attempt to mate, (2) did and did not mate, and (3) having attempted to mate did or did not mate. In these analyses we chose to use mid tibia length for our trait measurement and wing length as our body size measurement because this is commonly used as a standard body size measurement in flies. Using generalised linear mixed models with a binomial distribution and including trial as a random factor we first compared the variation in wing length and mid tibia length between all males that never attempted to mate and those that did. Secondly we compared between all males that did not mate successfully, including those that did not attempt to mate, and those that did. Finally, within those that attempted to mate the size difference between those that did and did not mate successfully. In addition, we investigated whether trait size relative to body size varied between males across the three different comparisons by including both mid tibia length and wing length in the models. These analyses provide us with additional estimates of selection on mid tibia length with the removal of any variation due to wing length. We also repeated analyses for relative size (difference between male and female size) by calculating the relative size difference in both wing length and mid tibia length between all pairs of flies that engaged in mating behaviour during all of the mating trials by subtracting the female's trait size from the male's. In addition to these analyses, and in order to provide more widely comparable selection estimates, we calculated standardised selection gradients by regressing relative male fitness against relative trait size (Blanckenhorn 2010; Lande and Arnold 1983). Relative fitness was calculated as the focal male's fitness divided by the average fitness of all the males within the trial. Z-scores were used to calculate both relative wing length and mid tibia length for each male within mating trial groups by subtracting from each male's trait size the average trait size of all the males in the trial and then dividing this value by the standard deviation of the all the males in the trial. Regressions of these standardised measures were then run for each trial and the slopes from each model were then averaged across the trials to produce a standardised selection gradient. Trait size and relative trait size were all normally distributed so no transformations of the data were carried out, and all analyses were carried out in R (R Core Team 2020). 


\section{Results}

\section{Trait variation in Chaetocoelopa littoralis and Coelopella curvipes}

On average $C$. littoralis were larger than $C$. curvipes, however there was overlap in the sizes of these species between larger $C$. curvipes and smaller $C$. littoralis (Table 1). Males of both species had higher coefficients of variation compared to females in all traits, with the greatest variation and difference in variation found in $C$. littoralis mid tibia length (Table 1). In C. curvipes, there was no significant difference in average size between males and females and no strong evidence of sexual dimorphism in any traits with the exception of mid tibia length (Table 1). In contrast, there was a significant difference in size between males and females of $C$. littoralis, with the average size of males larger across all traits, and strong evidence of sexual size dimorphism in both leg length measurements (Table 1).

There was an overall greater difference in size with sex in $C$. littoralis, with males often significantly larger in size, however, smaller flies of this species were very similar in size, with neither sex containing a group of proportionally smaller individuals (Table 2, Fig. 1).

We found no significant difference in slope or intercept between the sexes of $C$. curvipes when comparing variation in thorax length with wing length (Table 2, Fig. 1). In C. littoralis there was some evidence of a difference in intercept when comparing variation in thorax width with wing length between sexes (Table 2, Fig. 1). However, both species show the most significant variation in both slope and intercept between males and females when comparing variation in mid tibia length with wing length, with males of both species having longer mid tibiae, and with this difference becoming more pronounced with increasing body size (wing length) (Table 2, Fig. 1). There was also significant variation with mid femur length in $C$. littoralis, however, for $C$. curvipes mid femur length did not vary in slope between the sexes, but males did have comparatively larger mid femurs (Table 2, Fig. 1).

In all cases where the slope or elevation differed between males and females, males had steeper slopes and higher elevations compared to variation in females (Table 2, Fig. 1). Overall, these findings suggest that leg length in males of both species is under positive sexual selection, with particularly strong positive static allometry in midleg length in $C$. littoralis with slope values much greater than 1 (Table 2).

\section{General observations of mating behaviour in Chaetocoelopa littoralis}

During the mating trials we made a number of observations of the mating behaviour of C. littoralis. Firstly, all females attempted to vigorously remove any male attempting to mate by shaking their bodies and kicking out with their legs. Males that managed to successfully overcome these rejection responses would subsequently place their forelegs over the head of the female while mating. In addition, when a male overcame a female's rejection response, they often flicked both of their wings out and back several times, and when remaining with the female they placed their midlegs spread out directly perpendicular to the female's body. Premating struggles occurred too rapidly to observe whether any male legs were used to grasp the female and overcome resistance, but this remains a potential function.

It was common for multiple males to become involved in a mating attempt, and males were observed to detect and respond rapidly to mating activity nearby. 
唯量

s. 을

.5.

会

ㅍ.

帘

ن⿺辶⿻

국 홍

3 क

害苛

궁

II

की 娄

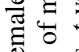

的的

तิ

$\approx . \Xi 0$

जै :

速贾

害告

泀氜

s.

次

总

论

$+$

帚

急 它

言.

․ำ

홀 은

厅

पै

过

क 8

$\because{ }^{\circ} \cdot$

$\Xi \stackrel{\Xi}{\Xi}$

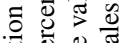

흘 률

疍

* * * * * * * * * * * * * * * *

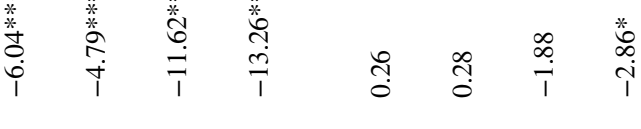

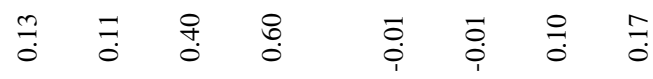

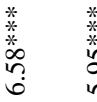

苂 $\stackrel{*}{*}$

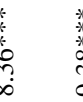

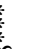

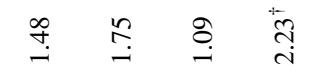

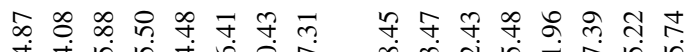

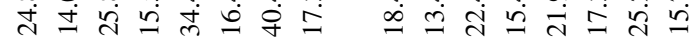

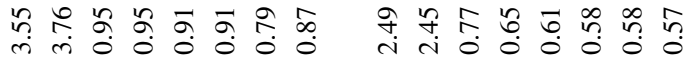

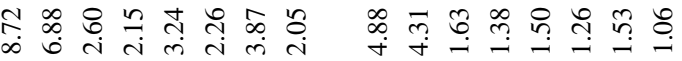

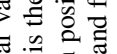

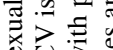

记

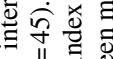

㲾

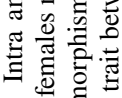

๘ें

능

N

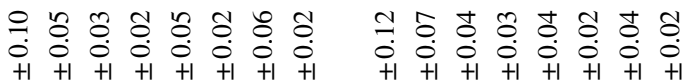

尚

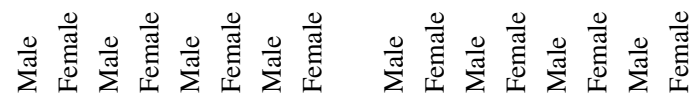


Table 2 Static allometries of both male and female Chaetocoelopa littoralis and Coelopella curvipes

\begin{tabular}{|c|c|c|c|c|c|c|}
\hline & \multirow[t]{2}{*}{ Sex } & \multirow[t]{2}{*}{$\mathrm{R}^{2}$} & \multicolumn{2}{|l|}{ Intercept } & \multicolumn{2}{|l|}{ Slope } \\
\hline & & & Estimate $(95 \% \mathrm{CI})$ & $F$ & Estimate (95\% CI) & $F$ \\
\hline \multicolumn{7}{|l|}{$\begin{array}{l}\text { Chaetocoelopa lit- } \\
\text { toralis }\end{array}$} \\
\hline \multirow[t]{2}{*}{ Thorax width } & Female & 0.85 & $\begin{array}{l}-1.26(-1.36 \\
-1.17)\end{array}$ & $15.03 * *$ & $1.03(0.97,1.09)$ & 0.12 \\
\hline & Male & 0.94 & $\begin{array}{l}-1.27(-1.36 \\
-1.21)\end{array}$ & & $1.02(0.99,1.05)$ & \\
\hline \multirow[t]{2}{*}{ Mid femur length } & Female & 0.87 & $\begin{array}{l}-1.45(-1.55 \\
-1.36)\end{array}$ & $704.9 * * *$ & $1.08 *(1.02,1.13)$ & $95.17 * * *$ \\
\hline & Male & 0.97 & $\begin{array}{c}-1.80(-1.85 \\
-1.75)\end{array}$ & & $1.38 * * *(1.35,1.41)$ & \\
\hline \multirow[t]{2}{*}{ Mid tibia length } & Female & 0.86 & $\begin{array}{l}-1.58(-1.68 \\
-1.48)\end{array}$ & $1080.00 * * *$ & $1.13 * * *(1.07,1.19)$ & $195.60 * * *$ \\
\hline & Male & 0.95 & $\begin{array}{l}-2.17(-2.23 \\
-2.10)\end{array}$ & & $1.63 * * *(1.59,1.66)$ & \\
\hline \multicolumn{7}{|l|}{ Coelopella curvipes } \\
\hline \multirow[t]{2}{*}{ Thorax width } & Female & 0.85 & $\begin{array}{l}-1.28(-1.46 \\
-1.11)\end{array}$ & 0.07 & $1.10(0.96,1.24)$ & 0.23 \\
\hline & Male & 0.93 & $\begin{array}{l}-1.34(-1.50 \\
-1.18)\end{array}$ & & $1.15^{\dagger}(1.02,1.27)$ & \\
\hline \multirow[t]{2}{*}{ Mid femur length } & Female & 0.84 & $\begin{array}{c}-1.56(-1.76 \\
-1.36)\end{array}$ & $44.79 * * *$ & $1.16^{\dagger}(1.00,1.32)$ & 0.00 \\
\hline & Male & 0.93 & $\begin{array}{c}-1.46(-1.61 \\
-1.30)\end{array}$ & & $1.16^{\dagger}(1.04,1.29)$ & \\
\hline \multirow[t]{2}{*}{ Mid tibia length } & Female & 0.82 & $\begin{array}{c}-1.53(-1.71 \\
-1.34)\end{array}$ & $93.42 * * *$ & $1.05(0.90,1.20)$ & $5.31^{\dagger}$ \\
\hline & Male & 0.92 & $\begin{array}{l}-1.66(-1.84 \\
-1.48)\end{array}$ & & $1.29 * *(1.14,1.44)$ & \\
\hline
\end{tabular}

$\mathrm{R}^{2}$ values indicate the correlating of the two variables, and all correlations were significant. Line coefficient values (intercept and slope) are presented from comparisons of variation in the traits thorax width, mid femur length, and mid tibia length with the body size measurement wing length using ordinary least squares regression. All variables were log transformed prior to analyses, and $95 \%$ confidence intervals around the estimates of both the intercept and slope are given. $F$-statistic values indicate whether there is a significant difference in the slope and intercept between males and females for each trait comparison. Slopes that are significantly different to isometry, and $F$-values that indicate a significant difference between the sexes in slope and intercept, are indicated by asterisks with $\dagger \mathrm{P}<0.05$, $* \mathrm{P}<0.01, * * \mathrm{P}<0.001, * * * \mathrm{P}<0.0001$

Furthermore, all males will attempt to mate with either sex seemingly indiscriminately, and mating behaviour in males seems to be stimulated by detecting the nearby presence of another fly.

In most trials only a small number of individuals engaged in any mating behaviour, with the same males often attempting to mate multiple times with the same female. Fewer than five mating attempts were observed in half of the trials, with one having no mating behaviour observed at all. The highest number of interactions observed in a single trial was 30 , with an average of $7.7 \pm 2.3$ (SE). Overall, a total of 127 mating attempts were observed, and mating was observed in $32 \%$ of interactions. 

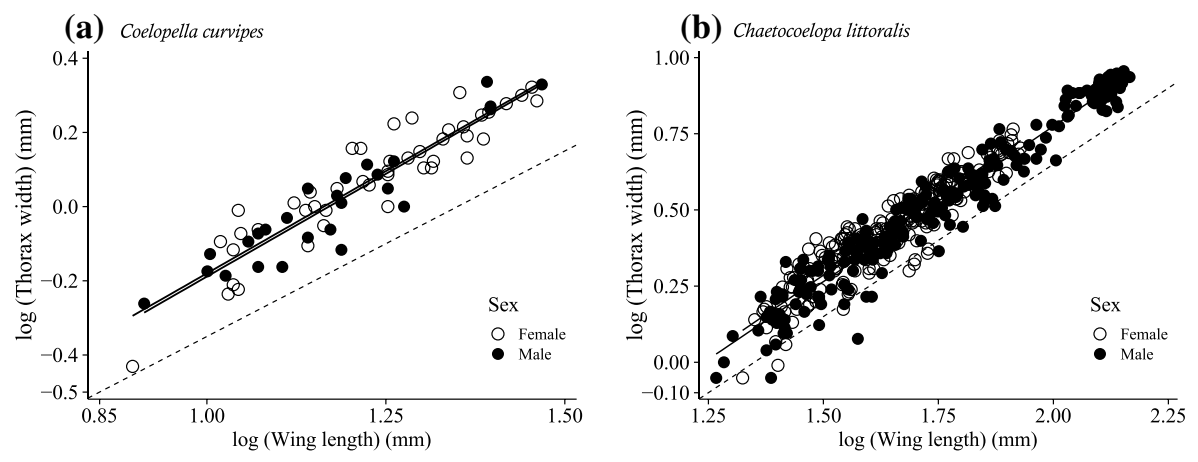

(c) Coelopella curvipes

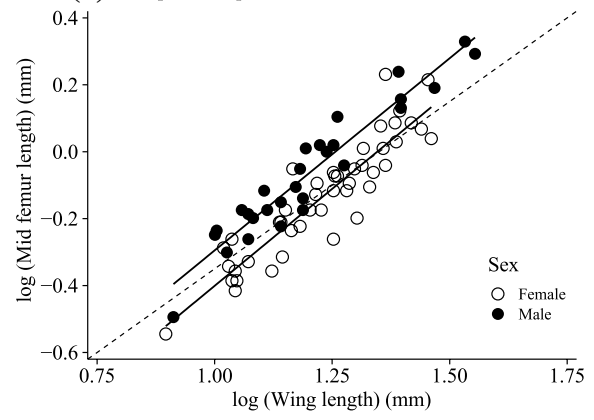

(d) Chaetocoelopa littoralis

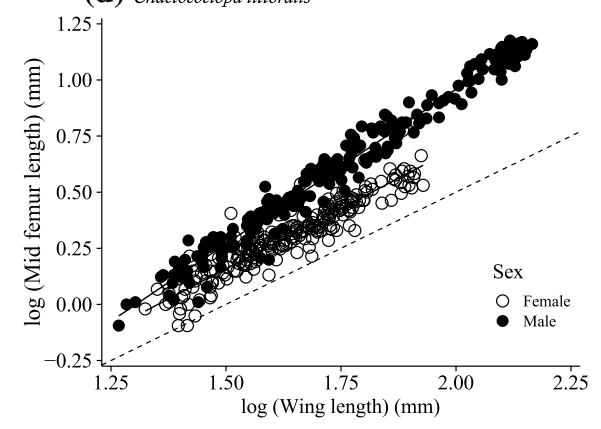

(e) Coelopella curvipes

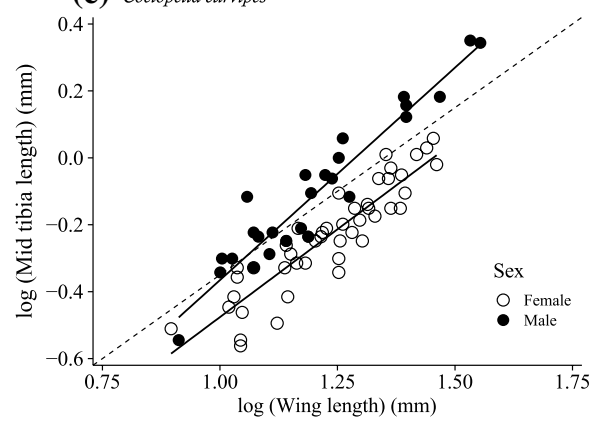

(f) Chaetocoelopa littoralis

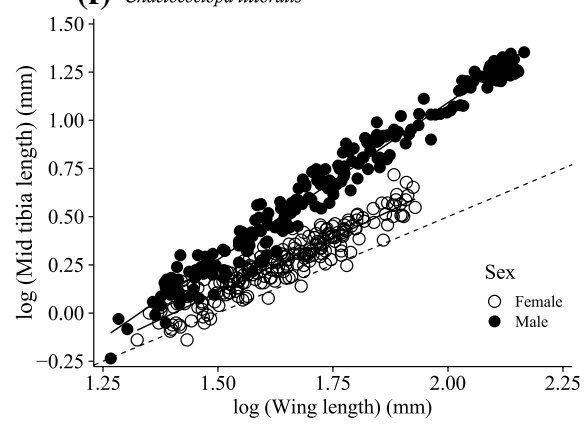

Fig. 1 Comparison of static allometry of thorax width, and mid femur and mid tibia length and with wing length, in two species of Coelopidae, Coelopella curvipes and Chaetocoelopa littoralis. Coefficient values for each species and sex can be found in Table 2. The dashed lines in each plot show a comparative isometric slope of 1

\section{Mating success with size}

Across all of the first trials, $29 \%$ of males attempted to mate, and $15 \%$ mated successfully, and of the males that attempted to mate, $52 \%$ mated successfully. Of the males that attempted to mate on average they made $2.58 \pm 0.39$ (SE) mating attempts over the hourlong trial period, with the maximum number of attempts made by a single male being 13 .

Wing length did not predict (a) whether males attempted to mate across all trials $\left(\beta_{1}=-0.109, \mathrm{SE}=0.192, z=-0.575, P=0.565\right)$ (Fig. $\left.2 \mathrm{~d}\right)$, or (b) whether males 

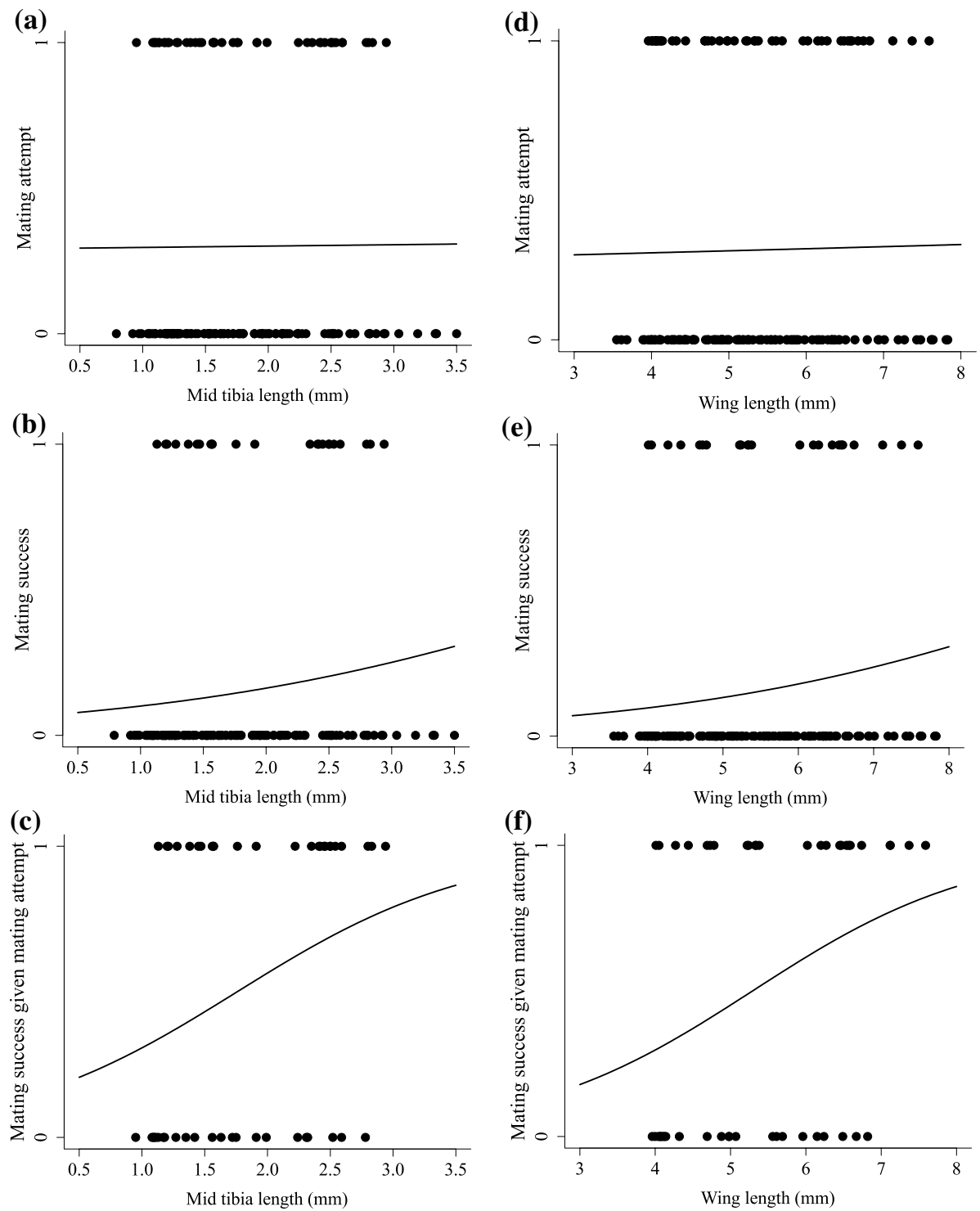

Fig. 2 Variation in trait size in males from mating trials with Chaetocoelopa littoralis. Plots $(\mathrm{a}-\mathrm{c})$ show a comparison of male mid tibia length of males which did or did not engage in mating interactions during trials (a), did or did not successful mate with at least one female during the trial (b), and did or did not successfully copulate during the trial across only males which attempted to mate (c). Plots (d-e) represent the equivalent comparisons paired with plots $(\mathrm{a}-\mathrm{c})$ but with wing length. Curves are fitted from linear models with a binomial distribution

successfully mated across all individuals $\left(\beta_{1}=0.249, \mathrm{SE}=0.232, z=1.074, P=0.283\right)$ (Fig. 2e). However, we did find for males that attempted to mate, that wing length predicted male mating success $\left(\beta_{1}=0.658, \mathrm{SE}=0.317, z=2.077, P=0.038\right)$ (Fig. 2f). Average wing length of all males that attempted to mate but did not mate successfully was 
$5.07 \pm 0.20 \mathrm{~mm}(\mathrm{SE})$, compared with the average wing length of all the males that did not successfully mate $5.25 \pm 0.09 \mathrm{~mm}(\mathrm{SE})$ ), both of which are shorter than average compared to those that did successfully mate $5.78 \pm 0.22 \mathrm{~mm}(\mathrm{SE})$.

We found that mid tibia length did not predict whether males attempted to mate $\left(\beta_{1}=-0.200, \mathrm{SE}=0.338, z=-0.593, P=0.553\right.$ ) (Fig. 2a). We also found that mid tibia length did not predict whether the males successfully mated when comparing all males $\left(\beta_{1}=0.394, \mathrm{SE}=0.408, z=0.967, P=0.333\right.$ ) (Fig. $2 \mathrm{~b}$ ). However, when focussing only on those males that attempted to mate there was a marginally non-significant trend towards higher mating success in those males with longer mid-tibiae $\left(\beta_{1}=1.042, \mathrm{SE}=0.559\right.$, $z=1.864, P=0.062$ ) (Fig. 2c). Average mid tibia length of all males that attempted to mate but did not mate successfully was $1.66 \pm 0.12$ (SE), compared with the average mid tibia length of all the males that did not successfully mate $1.75 \pm 0.05 \mathrm{~mm}(\mathrm{SE})$, both of which were shorter than average compared to those that did successfully mate $2.02 \pm 0.12$ (SE).

Furthermore, we found with the removal of variation due to body size from the models, that relative mid tibia length did not predict whether males attempted to mate $\left(\beta_{1}=-0.274\right.$, $\mathrm{SE}=1.766, z=-0.155, P=0.877)$, or whether males successfully mated $\left(\beta_{1}=-1.041\right.$, $\mathrm{SE}=2.179, z=-0.478, P=0.633)$. Of the males that attempted to mate, with the removal of variation due to body size, we also found that relative mid tibia length did not predict mating success $\left(\beta_{1}=-2.181, \mathrm{SE}=2.632, z=-0.829, P=0.407\right)$.

For each mating attempt, the relative difference in mid tibia length between males and females in a pair did not predict $\left(\beta_{1}=0.499, \mathrm{SE}=0.296, z=1.683, P=0.092\right)$ whether mating occurred (average difference $=0.42 \pm 0.05 \mathrm{~mm}(\mathrm{SE})$ ) or didn't (average difference $=0.29 \pm 0.04 \mathrm{~mm}(\mathrm{SE})$ ). Similarly, the relative difference in wing length did not predict mating success $\left(\beta_{1}=0.258, \mathrm{SE}=0.152, z=1.697, P=0.089\right)$. Both of these measurements of relative size difference did show trends $(p<0.1)$ towards males with relatively long wings/mid-tibiae compared to females, having higher mating success.

Standardised selection gradients were estimated to be $0.182 \pm 0.179$ (SE)) for relative mid tibia length and $0.171 \pm 0.163$ (SE) for relative wing length.

\section{Discussion}

We found significant sexual size dimorphism in measures of body size (wing and thorax) for Chaetocoelopa littoralis and in a trait (midlegs) predicted to be important in aspects of mating interactions in both C. littoralis and Coelopella curvipes. Positive static allometry was also particularly apparent for mid-tibiae and mid-femora of male $C$. littoralis and for mid-tibiae of male $C$. curvipes. In mating trials with $C$. littoralis, we found that larger males which attempt to mate are more likely to mate successfully. However, there is no significant difference in the size of males that do and do not attempt to mate, indicating that males of all sizes attempted to mate but that the largest were more successful. Interestingly, despite positive static allometry, male mid-tibia length was not a strong predictor of mating success, although this relationship was only marginally non-significant.

In other species of Coelopid males are typically larger on average than females and more variable in size (Crean et al 2000; Crean and Gilburn 1998; Dunn et al 1999; McAlpine 1991). While sexual size dimorphism was clear for $C$. littoralis, we did not find a difference in average wing length between male and female $C$. curvipes. This monomorphism is less common amongst the Coelopids where males are typically larger, but has been found in Gluma musgravei (Crean et al 2000). 
However, both sexes of both our species show greater variation in size (CV\%) compared to the variation found across other Coelopids (Crean et al 2000). Compared with the average wing lengths of the seven species reviewed by Crean et al (2000), C. curvipes is considerably smaller than all species, but $C$. littoralis males are larger on average than all but one of the other species (Coelopa nebularum).

The difference in size variation (CV) between the sexes in the two different species is interesting given their very similar niche requirements and general mating systems. However, C. littoralis is typically less abundant in the wild compared to C. curvipes, only increasing in abundance when there are large quantities of wrack, compared to $C$. curvipes which appears to be more generalist in its resource use (RLG - pers obs). In the two European Coelopid species Coelopa frigida and Coelopa pilipes which are often found inhabiting the same patches of wrack, larvae are known to have different distributions within the wrack, with $C$. frigida larvae found in cooler parts and $C$. pilipes in warmer areas (Phillips et al 1995). In addition, at low larval densities, growth and survival is facilitated for both species, whereas at higher densities there is competition (Leggett et al 1996). It is possible that there is a similar difference in resource requirements between $C$. curvipes and $C$. littoralis and that this drives the difference in trait size between these species.

We found longer midlegs, and in particular longer mid tibia, in both Coelopid species studied, and in both of these cases, they exhibited positive static allometry. In comparison to other published work on Coelopids which focus on wing length as a measure of body size, we chose to investigate mid-legs as they appeared noticeably longer in males, and we predicted they may have a function during mating interactions. We were also aware that positive allometry has been observed in other northern hemisphere Coelopid species (Andre Gilburn - pers. comm.). It is not unexpected to find positive allometry in male traits, however, it is interesting to describe this occurrence in a trait that is not used as either a weapon or ornament. It was predicted that these longer legs were conferring some significant advantage to males during coercive mating interactions which allows them to overcome the females pre-mating struggles and successfully mate. However, we found only a marginally non-significant trend towards this, with our measure of male body size proving a much better predictor. It is therefore unclear why larger males have disproportionally longer midlegs, given that their comparatively large size overall already provides them with a significant advantage in securing matings.

A possible unexplored function of the male midlegs is mate guarding. We observed C. littoralis using their midlegs in a mate-guarding type of behaviour where they held their legs out perpendicular to their body creating a wide boundary around themselves and the female. It is possible that this behaviour makes it more challenging for other males to detect the presence of the female, and at the same time allows the guarding male to detect the presence of other males at a greater distance. In other species including crane flies (Adler and Adler 1991), harlequin beetles (Zeh and Zeh 1992) and cave wētā (Fea and Holwell 2018a), males extend their legs in a similar fashion during mating and mate-guarding. The male hindlegs of cave wētā Pachyrhamma waitomoensis are highly exaggerated relative to females, yet are hypoallometric (Fea and Holwell 2018b). While male hindleg length in this species has no influence over mating interruptions by rival males, it does correlate with the number of matings a male can achieve by deflecting heterospecific animals in the densely populated communities occurring on cave walls (Fea and Holwell 2018a). In other species of Coelopid it has been suggested that longer midlegs may be advantageous in remaining attached to females during struggling behaviour as they are used in stabilisation or to clasp the females (Andre Gilburn - pers comm; Crean et al 2000). Males of Coelopa vanduzeei have notably long legs, and the 
fore and hind legs are used to grip the females while the midlegs are used to stabilise the males in position (Crean et al 2000). It is possible the longer midlegs of male $C$. littoralis provide an advantage in regards to securing and stabilising a male in position during mating, and subsequently guarding their mates and further observations of how C. littoralis use these long midlegs is required. In general, the allometry and selective advantage of leg length in mate-guarding species is virtually unstudied and would be a fruitful area for future research.

This observation is supported by our findings, which indicate that larger body size is important for successfully securing matings in $C$. littoralis, in comparison to leg length which has a (marginally) non-significant effect on success. It is possible that larger males may adopt slightly different mating strategies compared to smaller males. Small maleswhich are more frequently rejected in mating interactions-expend more energy attempting to mate more frequently to increase their chances of success. Larger males-which invest more in having disproportionally longer legs - may need fewer attempts to achieve mating success, and similarly long legs may not improve a small male's success. Smaller adult males may also emerge sooner in the population, attempting to mate rapidly and frequently to secure some mating success which may not be increased by investing in longer legs.

It is important however to note that the existence of positive static allometry in a trait does not necessarily imply the influence of sexual selection. Bonduriansky (2007) demonstrated that many traits that are under sexual selection do not exhibit positive static allometry, and that many positively allometric traits show no evidence of being under sexual selection. Positive static allometry indicates a marginal fitness gain to larger individuals by investing in disproportionately large traits (Bonduriansky and Day 2003), but whether or not this gain is driven by sexual selection needs to be demonstrated (Bonduriansky 2007). For $C$. littoralis, we did not find mid-tibia length to strongly predict male mating success, but this relationship was only marginally non-significant $(p=0.062)$. It is possible therefore, that more investigation may reveal a sexually selected function for midlegs, or that the benefit of longer midlegs is entirely unrelated to mating interactions.

On average larger male $C$. littoralis achieved higher mating success. This is a common finding from other studies of Coelopids, where larger males are more successful, including all five Coelopid species studied by Crean et al (2000). Males of larger size in many Coelopids are more likely to overcome intense sexual conflict and pre-mating struggles from females as they are able to resist behaviours such as shaking and kicking by the female without being dislodged (Blyth and Gilburn 2011; Crean et al 2000; Day et al 1990). We found that $C$. littoralis females exhibit similar resistance behaviours, and that there is likely strong selection on traits that allow males to overcome this resistance. In this case, large body size allowed males to overcome the initial rejection response of females and achieve mating success. It seems that $C$. littoralis follows the same pattern that has been shown to occur across multiple coelopids, where sexual conflict via a ubiquitous female rejection response, drives sexual selection on male body size (Blyth and Gilburn 2011; Crean et al 2000; Day et al 1990). Finally, the observation that male $C$. littoralis place their forelegs over the head of the female during mating is a behaviour which has been previously described in $C$. frigida and was found to increase male mating success (Crocker and Day 1987; Day et al 1990, 1987).

In summary, we have found both similarities and considerable differences in the size variation of two species of Coelopid from AotearoalNew Zealand which we hypothesise is linked to variation in their ecology. Furthermore, we have demonstrated in a coercive mating system the existence of positive static allometry for a trait whose function is still 
somewhat unclear. Finally, we have found that similar to other research on Coelopids, a mating advantage for larger males of $C$. littoralis under dynamic experimental conditions.

Acknowledgements We would like to thank the marine technicians Peter Schlegel and Esther Stuck at that University of Auckland for their support in collecting kelp for maintaining the kelp fly population. In addition we would like to thank our summer research student Jaynie Yang for measuring many of the flies used in this study. R J LeGrice was supported by a University of Auckland Doctoral Scholarship.

Authors contribution Conceptualisation: R J LeGrice and G I Holwell; Methodology: R J LeGrice and G I Holwell; Formal analysis and investigation: R J LeGrice; Writing - original draft preparation: R J LeGrice and G I Holwell; Writing - review and editing: R J LeGrice and G I Holwell; Supervision: G I Holwell.

Funding Open Access funding enabled and organized by CAUL and its Member Institutions. Not applicable.

Data availability The datasets generated during and/or analysed during the current study are available in the Figshare repository, [https://doi.org/10.6084/m9.figshare.17303921].

\section{Declarations}

Conflict of interest The authors declare that they have no conflict of interest.

Ethics approval Not applicable.

Consent to participate Not applicable.

Consent for publication Not applicable.

Open Access This article is licensed under a Creative Commons Attribution 4.0 International License, which permits use, sharing, adaptation, distribution and reproduction in any medium or format, as long as you give appropriate credit to the original author(s) and the source, provide a link to the Creative Commons licence, and indicate if changes were made. The images or other third party material in this article are included in the article's Creative Commons licence, unless indicated otherwise in a credit line to the material. If material is not included in the article's Creative Commons licence and your intended use is not permitted by statutory regulation or exceeds the permitted use, you will need to obtain permission directly from the copyright holder. To view a copy of this licence, visit http://creativecommons.org/licenses/by/4.0/.

\section{References}

Adler PH, Adler CR (1991) Mating behavior and the evolutionary significance of mate guarding in three species of crane flies (Diptera: Tipulidae). J Insect Behav 4:619-632

Alcock J (1994) Postinsemination associations between males and females in insects: the mate-guarding hypothesis. Annu Rev Entomol 39:1-21

Andersson M (1986) Evolution of condition-dependent sex ornaments and mating preferences: sexual selection based on viability differences. Evolution 40:804-816

Andersson M (1994) Sexual selection. Princeton University Press, New Jersey

Arnqvist G (1992) Pre-copulatory fighting in a water strider: inter-sexual conflict or mate assessment? Anim Behav 43:559-567

Arnqvist G, Rowe L (2002) Correlated evolution of male and female morphologies in water striders. Evolution 56:936-947

Arnqvist G, Rowe L (2005) Sexual conflict. Princeton University Press, New Jersey

Baena M, Eberhard W (2007) Appearances deceive: female "resistance" behaviour in a sepsid fly is not a test of male ability to hold on. Ethol Ecol Evol 19:27-50

Blanckenhorn W (2010) The quantitative study of sexual selection and natural selection in the wild and in the laboratory. In: Kappeler P (ed) Animal behaviour: evolution and mechanisms. Springer, Berlin, Heidelberg, pp 301-327 
Blanckenhorn W, Muhlhauser C, Morf C, Reusch T, Reuter M (2000) Female choice, female reluctance to mate and sexual selection on body size on the dung fly Sepsis cynipsea. Ethology 106:577-593

Blanckenhorn WU, Hosken DJ, Martin OY, Reim C, Teuschl Y, Ward PI (2002) The costs of copulating in the dung fly Sepsis cynipsea.Behav Ecol 13:353-358

Blyth JE, Gilburn AS (2006) Extreme promiscuity in a mating system dominated by sexual conflict. J Insect Behav 19:447-455

Blyth JE, Gilburn AS (2011) The function of female behaviours adopted during premating struggles in the seaweed fly, Coelopa frigida. Anim Behav 81:77-82

Bonduriansky R (2007) Sexual selection and allometry: a critical reappraisal of the evidence and ideas. Evolution 61:838-849

Bonduriansky R, Day T (2003) The evolution of static allometry in sexually selected traits. Evolution 57:2450-2458

Briceño R, Eberhard W (2017) Copulatory dialogues between male and female Tsetse flies (Diptera: Muscidae: Glossina pallidipes). J Insect Behav 30:394-408

Burnet B (1960) The European species of the genus Coelopa (Dipt., Coelopidae). Entomol Mon Mag 96:8-13

Butlin R, Day T (1985) Adult size, longevity and fecundity in the seaweed fly, Coelopa frigida. Heredity 54:107-110

Chapman T, Arnqvist G, Bangham J, Rowe L (2003) Sexual conflict. Trends Ecol Evol 18:41-47

Crean CS, Gilburn AS (1998) Sexual selection as a side-effect of sexual conflict in the seaweed fly, Coelopa ursina (Diptera: Coelopidae). Anim Behav 56:1405-1410

Crean CS, Dunn DW, Day TH, Gilburn AS (2000) Female mate choice for large males in several species of seaweed fly (Diptera: Coelopidae). Anim Behav 59:121-126

Crocker G, Day T (1987) An advantage to mate choice in the seaweed fly, Coelopa frigida. Behav Ecol Sociobiol 20:295-301

Crudgington HS, Siva-Jothy MT (2000) Genital damage, kicking and early death. Nature 407:855-856

Cullen SJ, Young AM, Day TH (1987) Dietary requirements of seaweed flies (Coelopa frigida). Estuar Coast Shelf S 24:701-710

Day TH, Gilburn AS (1997) Sexual selection in seaweed flies. Adv Stud Behav 26:1-57

Day TH, Miles S, Pilkington MD, Butlin RK (1987) Differential mating success in populations of seaweed flies (Coelopa frigida). Heredity 58:203-212

Day TH, Foster SP, Engelhard G (1990) Mating behavior in seaweed flies (Coelopa frigida). J Insect Behav 3:105-120

Dobson T (1974) Studies on the biology of the kelp-fly Coelopa in Great Britain. J Nat Hist 8:155-177

Dunn DW, Crean CS (2002) The effects of exposure to seaweed on willingness to mate, oviposition, and longevity in seaweed flies. Ecol Entomol 27:554-564

Dunn DW, Crean CS, Wilson CL, Gilburn AS (1999) Male choice, willingness to mate and body size in seaweed flies (Diptera: Coelopidae). Anim Behav 57:847-853

Dutto MS, Calbacho-Rosa L, Peretti AV (2011) Signalling and sexual conflict: female spiders use stridulation to inform males of sexual receptivity. Ethology 117:1040-1049

Eberhard WG (2001) The functional morphology of species-specific clasping structures on the front legs of male Archisepsis and Palaeosepsis flies (Diptera, Sepsidae). Zool J Linn Soc-Lond 133:335-368

Eberhard WG (2002) The function of female resistance behavior: Intromission by male coercion vs. female cooperation in sepsid flies (Diptera : Sepsidae). Rev Biol Trop 50:485-505

Eberhard WG, Rodríguez RL, Huber BA, Speck B, Miller H, Buzatto BA, Machado G (2018) Sexual selection and static allometry: the importance of function. Q Rev Biol 93:207-250

Edward DA, Gilburn AS (2007) The effect of habitat composition on sexual conflict in the seaweed flies Coelopa frigida and C. pilipes. Anim Behav 74:343-348

Egglishaw HJ (1960) Studies on the family Coelopidae (Diptera). Ecol Entomol 112:109-140

Emlen DJ, Warren IA, Johns A, Dworkin I, Lavine LC (2012) A mechanism of extreme growth and reliable signaling in sexually selected ornaments and weapons. Science 337:860-864

Fea M, Holwell G (2018a) Combat in a cave-dwelling wētā (Orthoptera: Rhaphidophoridae) with exaggerated weaponry. Anim Behav 138:85-92

Fea M, Holwell GI (2018b) Exaggerated male legs increase mating success by reducing disturbance to females in the cave wētā Pachyrhamma waitomoensis. Proc Roy Soc B 285(1880):20180401

Fowler-Finn KD, Triana E, Miller OG (2014) Mating in the harvestman Leiobunum vittatum (Arachnida: Opiliones): from premating struggles to solicitous tactile engagement. Behaviour 151:1663-1686

Geist V, Bayer M (1988) Sexual dimorphism in the Cervidae and its relation to habitat. J Zool 214:45-53

Gilburn AS, Day TH (1994) Sexual dimorphism, sexual selection and the $\alpha \beta$ chromosomal inversion polymorphism in the seaweed fly, Coelopa frigida. P Roy Soc Lond B Bio 257:303-309 
Hosken DJ, Stockley P (2004) Sexual selection and genital evolution. Trends Ecol Evol 19:87-93

Huxley JS, Tessier G (1936) Terminology of relative growth. Nature 137:780-781

Khila A, Abouheif E, Rowe L (2012) Function, developmental genetics, and fitness consequences of a sexually antagonistic trait. Science 336:585-589

Kilmer JT, Rodríguez RL (2017) Ordinary least squares regression is indicated for studies of allometry. J Evol Bio 30:4-12

Kirkpatrick M (1982) Sexual selection and the evolution of female choice. Evolution 36:1-12

Kodric-Brown A, Sibly RM, Brown JH (2006) The allometry of ornaments and weapons. PNAS 103:8733-8738

Lande R, Arnold SJ (1983) The measurement of selection on correlated characters. Evolution 37:1210-1226

Leggett M, Wilcockson R, Day T, Phillips D, Arthur W (1996) The genetic effects of competition in seaweed flies. Biol J Linn Soc Lond 57:1-11

Lovich JE, Gibbons JW (1992) Review of techniques for quantifying sexual size dimorphism. Growth Develop Aging 56:296-281

Mathis WN, McAlpine DK (2011) A catalogue and conspectus on the family Coelopidae (Diptera: Schizophora). In: Brake I, Thompson FC (eds) Contributions to the Systema Dipterorum (Insecta: Diptera). North American Dipterists Society \& Pensoft Publishers, Sofia, Bulgaria, pp 171-205

Mayhew AW (1939) Studies on the structure and life-history of the store-flies of the Genus Coelopa. Dissertation, Newcastle upon Tyne University

McAlpine DK (1991) Review of the Australian kelp flies Diptera: Coelopidae. Syst Entomol 16:29-84

Mead LS, Arnold SJ (2004) Quantitative genetic models of sexual selection. Trends Ecol Evol 19:264-271

Moller A, Pomiankowski A (1993) Why have birds got multiple sexual ornaments? Behav Ecol Sociobiol $32: 167-176$

O’Brien DM, Allen CE, Van Kleeck MJ, Hone D, Knell R, Knapp A, Christiansen S, Emlen DJ (2018) On the evolution of extreme structures: static scaling and the function of sexually selected signals. Anim Behav 144:95-108

Olsson M (1995) Forced copulation and costly female resistance behavior in the Lake Eyre dragon, Ctenophorus maculosus. Herpetologica 51:19-24

Parker GA (1972a) Reproductive behaviour of Sepsis cynipsea (L.) (Diptera: Sepsidae) I. A preliminary analysis of the reproductive strategy and its associated behaviour patterns. Behaviour 41:172-205

Parker GA (1972b) Reproductive behaviour of Sepsis cynipsea (L.)(Diptera: Sepsidae) II. The significance of the precopulatory passive phase and emigration. Behaviour 41:242-250

Parker GA (1979) Sexual selection and sexual conflict. In: Blum MS, Blum NA (eds) Sexual Selection and Reproductive Competition in Insects. Academic, New Jersey

Petrie M (1992) Are all secondary sexual display structures positively allometric and if so, why? Anim Behav 43:173-175

Phillips DS, Leggett M, Wilcockson R, Day TH, Arthur W (1995) Coexistence of competing species of seaweed flies: the role of temperature. Ecol Entomol 20:65-74

Puniamoorthy N, Su KF-Y, Meier R (2008) Bending for love: losses and gains of sexual dimorphisms are strictly correlated with changes in the mounting position of sepsid flies (Sepsidae: Diptera). BMC Evol Biol 8:155

R Core Team (2020) R: A language and environment for statistical computing. Austria, Vienna

Rico-Guevara A, Hurme KJ (2019) Intrasexually selected weapons. Biol Rev 94:60-101

Rohner PT, Blanckenhorn WU (2018) A comparative study of the role of sex-specific condition dependence in the evolution of sexually dimorphic traits. Am Nat 192:E202-E215

Rowe L (1992) Convenience polyandry in a water strider: foraging conflicts and female control of copulation frequency and guarding duration. Anim Behav 44:189-202

Rowe L, Westlake KP, Currie DC (2006) Functional significance of elaborate secondary sexual traits and their evolution in the water strider genus Rheumatobates. Can Entomol 138:568-577

Shuker DM, Day TH (2001) The repeatability of a sexual conflict over mating. Anim Behav 61:755-762

Thornhill R, Alcock J (1983) The evolution of insect mating systems. Harvard University Press, Cambridge

Weall CV, Gilburn AS (2000) Factors influencing the choice of female mate rejection strategies in the seaweed fly Coelopa nebularum (Diptera: Coelopidae). J Insect Behav 13:539-552

Weigensberg I, Fairbairn D (1994) Conflicts of interest between the sexes: a study of mating interactions in a semiaquatic bug. Anim Behav 48:893-901

Zar JH (1999) Biostatistical analysis. Prentice Hall, Upper Saddle River, New Jersey

Zeh DW, Zeh JA (1992) Sexual selection and sexual dimorphism in the harlequin beetle Acrocinus longimanus. Biotropica 24:86-96 
Publisher's Note Springer Nature remains neutral with regard to jurisdictional claims in published maps and institutional affiliations. 